Supplementary Information for

Vibrational Stark Effects of Carbonyl Probes Applied to Reinterpret IR and Raman Data for Enzyme Inhibitors in Terms of Electric Fields at the Active Site

Samuel H. Schneider and Steven G. Boxer*

Department of Chemistry, Stanford University, Stanford, California 94305-5012, United States

*Corresponding author. E-mail: sboxer@stanford.edu

\title{
Contents
}

1. Supplementary Figures

1.1 Vibrational Stark spectrum of oxoesters

1.2 Vibrational Stark spectrum of amides

1.3 IR solvatochromism of methyl trans-cinnamate

1.4 Relation between the reaction coordinate geometry, active site electric field, and activation free energy

\section{Supplementary Tables}

2.1 Vibrational solvatochromism and electric fields from MD simulations

2.2 Comparison of Stark tuning rates from VSS and field-frequency correlations

3. References 


\section{Supplementary Figures}
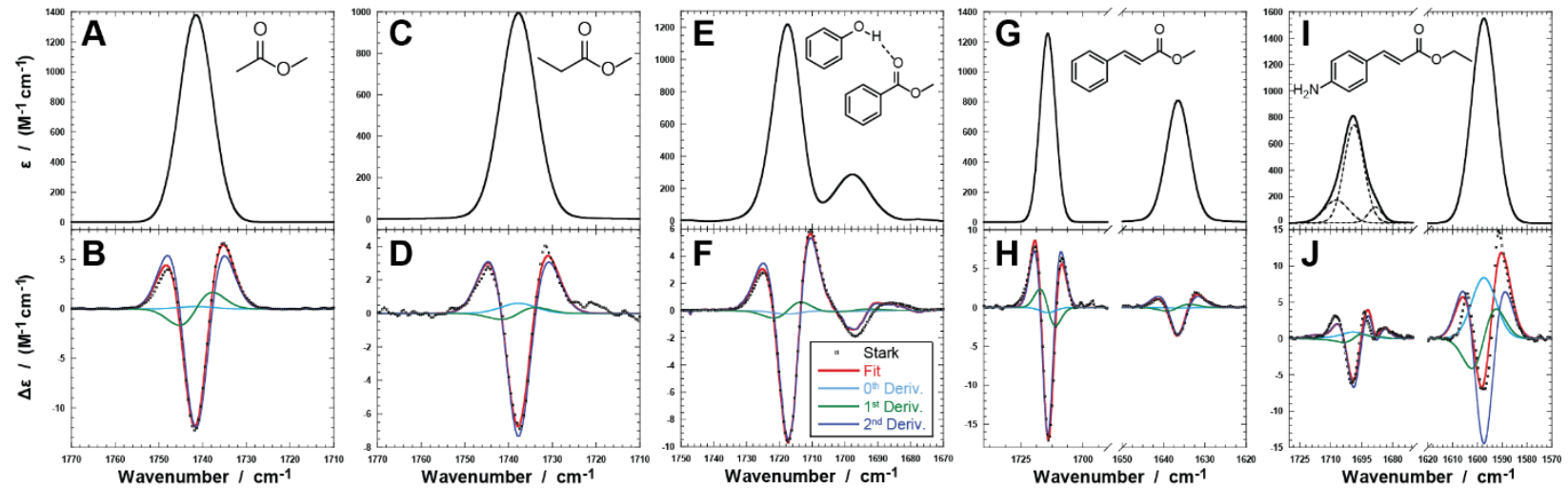

Figure S1. Infrared absorption and Stark spectra for various oxoester compounds. The infrared absorption spectrum of the $\mathrm{C}=\mathrm{O}$ stretch of $(\mathrm{A}) 50 \mathrm{mM}$ methyl acetate, (C) $50 \mathrm{mM}$ methyl propionate, (E) $150 \mathrm{mM}$ methyl benzoate in the presence of $50 \mathrm{mM}$ phenol, (G) $100 \mathrm{mM}$ methyl trans-cinnamate $\left(\mathrm{C}=\mathrm{C}\right.$ stretch on right, $\bar{v}=1636.5 \mathrm{~cm}^{-}$ ${ }^{1}, \varepsilon_{\max }=811 \mathrm{M}^{-1} \mathrm{~cm}^{-1}, \mathrm{FWHM}=6.6 \mathrm{~cm}^{-1}$ ), and (I) $100 \mathrm{mM}$ ethyl 4-aminocinnamate (C-N stretch on right, $\bar{v}=1597.2 \mathrm{~cm}^{-1}$, $\left.\varepsilon_{\max }=1550 \mathrm{M}^{-1} \mathrm{~cm}^{-1}, \mathrm{FWHM}=11.7 \mathrm{~cm}^{-1}\right)$ in glass forming solvents at $77 \mathrm{~K}$. The corresponding Stark spectrum (-) of (B) methyl acetate, (D) methyl propionate, (F) methyl benzoate, $(\mathrm{H})$ methyl trans-cinnamate $\left(\left|\Delta \vec{\mu}_{C=c}\right| f=0.58 \mathrm{~cm}^{-}\right.$ $1 /(\mathrm{MV} / \mathrm{cm}))$, and $(\mathrm{J})$ ethyl 4-aminocinnamate $\left(\left|\Delta \vec{\mu}_{C-N}\right| f=1.51 \mathrm{~cm}^{-1} /(\mathrm{MV} / \mathrm{cm})\right)$ in glass-forming solvents at $77 \mathrm{~K}$ scaled to $1.0 \mathrm{MV} / \mathrm{cm}$ with fit (red) and derivative contributions (cyan, green, blue). Dashed lines are Voigt profiles fit to the absorbance spectrum.
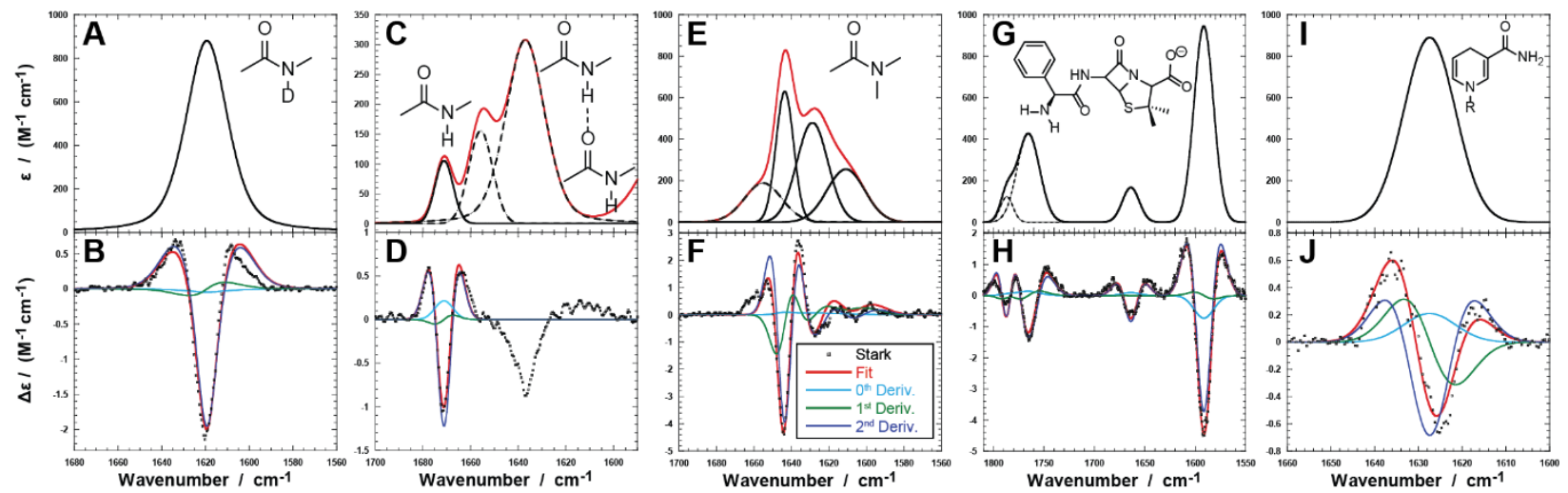

Figure S2. Infrared absorption and Stark spectra for various amide compounds. The infrared absorption spectrum of the $\mathrm{C}=\mathrm{O}$ stretch of $(\mathrm{A}) 200 \mathrm{mM} \mathrm{N}$-methylacetamide (N-deuterated), (C) $100 \mathrm{mM} \mathrm{N}$-methylacetamide, (E) $100 \mathrm{mM} \mathrm{N}, N$-dimethylacetamide, (G) $100 \mathrm{mM}$ ampicillin (asymmetric COO stretch on far right, $\bar{v}=1591.5 \mathrm{~cm}^{-1}$, $\varepsilon_{\max }=945 \mathrm{M}^{-1} \mathrm{~cm}^{-1}, \mathrm{FWHM}=22.9 \mathrm{~cm}^{-1}$ ), and (I) $93 \mathrm{mM} \mathrm{NADPH}$ in glass forming solvents at $77 \mathrm{~K}$. The corresponding Stark spectrum (घ) of (B) N-methylacetamide, (D) N-methylacetamide, (F) N,N-dimethylacetamide, (H) ampicillin $\left(\left|\Delta \vec{\mu}_{C O O-}\right| f=1.93 \mathrm{~cm}^{-1} /(\mathrm{MV} / \mathrm{cm})\right)$, and $(\mathrm{J}) \mathrm{NADPH}$ in glass-forming solvents at $77 \mathrm{~K}$ scaled to $1.0 \mathrm{MV} / \mathrm{cm}$ with fit (red) and derivative contributions (cyan, green, blue). The Stark spectra were fit using only the solid black Voigt profiles as shown in $(C),(E)$, and $(G)$ while the red line is the full absorbance spectra with corresponding peaks shown in either solid or dashed traces. 


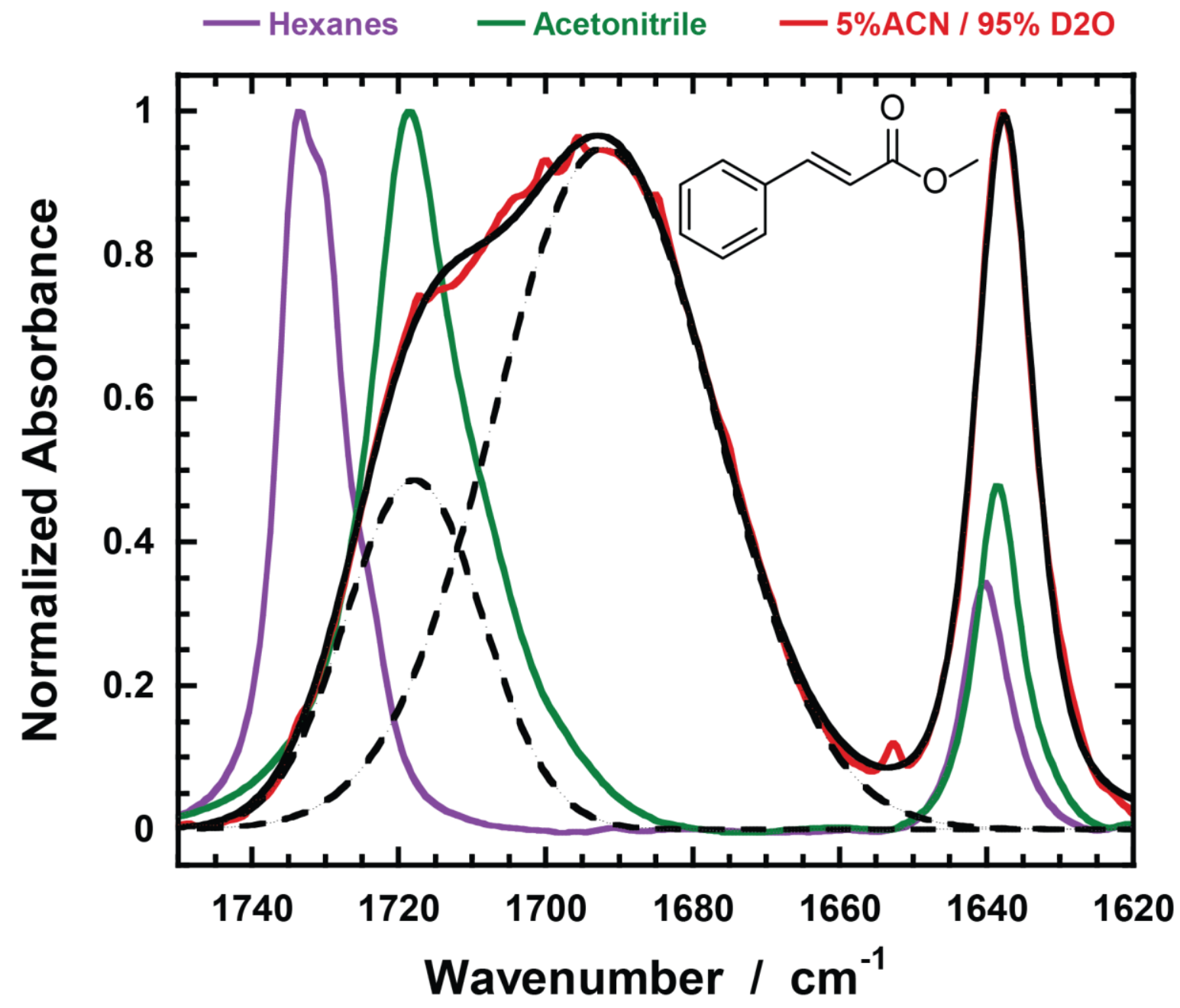

Figure S3. Vibrational solvatochromism of methyl trans-cinnamate. Infrared spectra of approximately $10 \mathrm{mM}$ methyl trans-cinnamate in hexanes, acetonitrile, and $5 \%$ acetonitrile/ $95 \% \mathrm{D}_{2} \mathrm{O}$ due to poor water solubility. The broad acetonitrile/ $\mathrm{D}_{2} \mathrm{O}$ lineshape can be fit to two peaks (dashed curves) that correspond to the carbonyl in acetonitrile $\left(1719 \mathrm{~cm}^{-1}\right)$ and $\mathrm{D}_{2} \mathrm{O}\left(1692 \mathrm{~cm}^{-1}\right)$. Note the solvatochromic shift in the $\mathrm{C}=\mathrm{C}$ mode at ca. $1640 \mathrm{~cm}^{-1}$. 
(a) Enolate TS

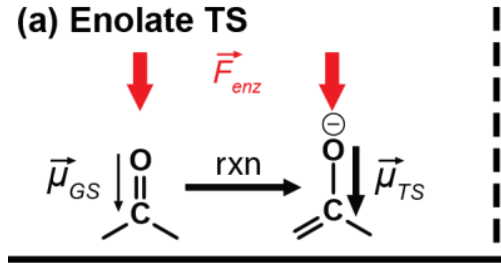

I (b) Tetrahedral TS
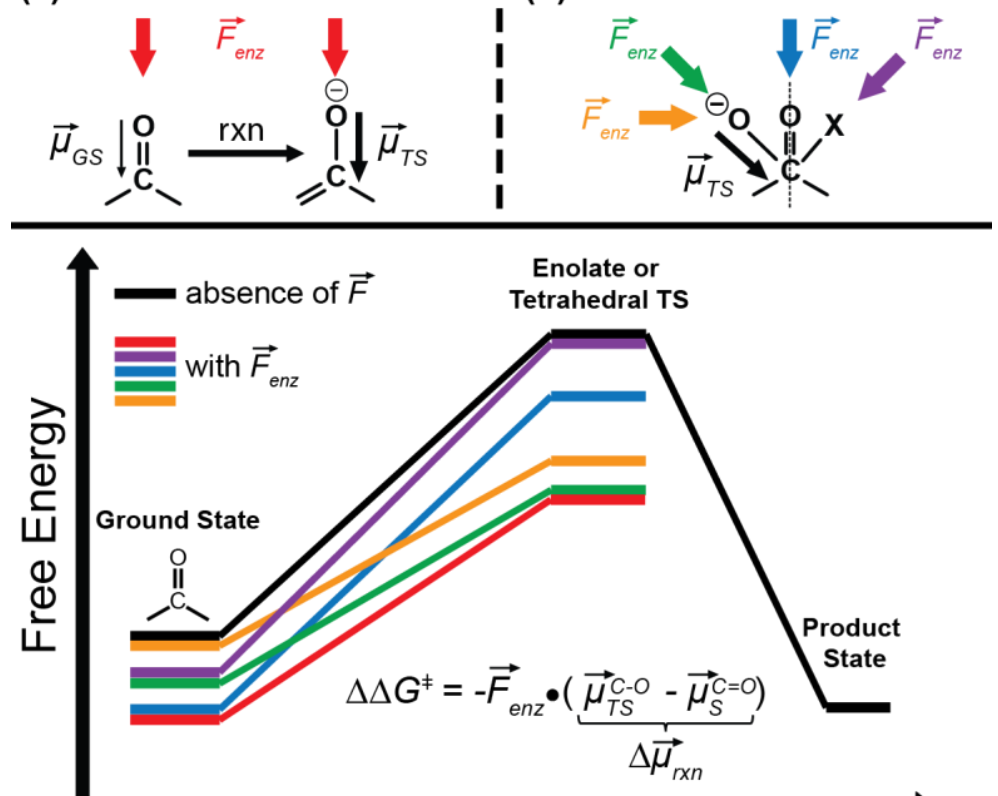

Reaction Coordinate

Figure S4. Effect of electric field orientation on the reaction activation barrier. For the two major classes of carbonyl chemical reactions, where the transition state is either an (a) enolate or (b) tetrahedral geometry, the possible effects of an enzyme's electric field orientation (colored arrows) on a reaction can be understood in terms of $\Delta \Delta G^{\ddagger}$. The direction of the arrows is a simplified representation of possible directions of the enzyme electric field relative to the ground state $(\mathrm{C}=\mathrm{O})$ and transition state $\left(\mathrm{C}-\mathrm{O}^{-}\right)$dipoles $(\vec{\mu})$. The effect of these different orientations on $\Delta \Delta \mathrm{G}^{\ddagger}$ are depicted, where the rate enhancements decrease in the order of orange, green, red, blue, purple. The black lines represent the situation in the absence of a field from the enzyme, and we do not consider any effect on the product state.

Expanding upon the discussion in the main text, a change in orientation of the bond axis over the reaction coordinate provides a potential mechanism by which an enzyme can achieve large rate enhancements in terms of $\Delta \Delta G^{\ddagger}=-\vec{F}_{\text {enz }} \bullet\left(\vec{\mu}_{T S}^{C-O}-\vec{\mu}_{S}^{C=O}\right)$. Among reactions containing carbonyl substrates, many of the transition states can be classified as either enolate (Figure S4a) or tetrahedral (Figure S4b) geometries. In the former, as exemplified in KSI and Dehalogenase, the orientation of the $\mathrm{C}-\mathrm{O}$ bond axis is approximately the same in the ground and transition states, and thus has the same projection of the active site electric field (red). As such, the enzyme can only lower the activation free energy by increasing the active site electric field and exploit the generally larger magnitude of $\vec{\mu}_{T S}^{C-O}$ relative to $\vec{\mu}_{S}^{C=O}$. In contrast, we can consider a reaction that proceeds through a tetrahedral transition state, simplified in Figure S4b as a displacement in the plane of the molecule; though this is not necessarily true we use this to keep the picture as simple as possible. The relative change in orientation between the $\mathrm{C}=\mathrm{O}$ and $\mathrm{C}-\mathrm{O}^{-}$bond axes provides the enzyme with a possibility to discriminate how the transition state and ground state are affected beyond a difference in the magnitude of their respective dipoles.

This effect of the orientation of the enzymes electric field with respect to the ground and transition state dipoles can be visualized in the simple model in Figure S4b, where the colored arrows denote the relative orientation of the enzyme active site's electric field with respect to the 
ground and transition state bond axes. As shown in the lower part of the figure, in the case of an electric field oriented along the transition state dipole (green), one expects a preferential stabilization of the transition state, though there will still be some ground state stabilization, reducing the activation barrier. In the case of the electric field oriented perpendicular to the ground state carbonyl (orange), there will be no ground state stabilization and all of the rate enhancement will arise from transition state stabilization. An electric field that is oriented along the ground state dipole (blue), will have lower transition state stabilization, and will only facilitate catalysis if the magnitude of the transition state dipole can offset this directed stabilization of the ground state. Finally, one can imagine the anti-catalytic case in which the electric field is perpendicular to the transition state dipole (purple), and the electric field results in purely ground state stabilization.

As exemplified in this simple diagram, the evolution of an enzyme that catalyzes a reaction with a tetrahedral transition state would likely converge towards an active site electric field that lies predominantly along the transition state bond axis (orange or green). The extent to which it can preferentially stabilize the transition state relative to the ground state will reflect the preorganization of the enzyme. As described in the main text, the negative correlation observed in cysteine proteases between the $\mathrm{C}=\mathrm{O}$ experienced electric field and the catalytic rate suggests that the mutations are likely altering the orientation of the enzyme electric field with respect to the acyl-intermediate probe from a geometry resembling the blue or green arrow towards orange. For serine proteases, the observed positive correlation between the active site electric field, as reported by the $\mathrm{C}=\mathrm{O}$ probes, and the activation free energy may suggest that both the magnitude and orientation are altered by mutation with the active site electric field somewhere between the green and blue cases above. As such, we would hypothesize that cysteine proteases are more preorganized than serine proteases, and can fully harness these differences in the reaction coordinate for catalytic advantage. This relationship between ground and transition state stabilization likely has important consequences in binding vs. rate tradeoffs as well as protein design. Finally, we stress that these drawings are highly simplified and meant to illustrate trends; state of the art transition state and electrostatic modeling would be applied to any particular reaction to estimate the effect. 


\section{Supplementary Tables}

Table S1. Vibrational solvatochromism and calculated electric fields from MD simulations. Peak positions as determined using either peak-picking or curve-fitting techniques and corresponding FWHM. The reported errors of the calculated electric field were determined from the correlation-adjusted error. ${ }^{1}$

\begin{tabular}{|c|c|c|c|c|c|c|c|}
\hline & & $\begin{array}{l}\text { peak- } \\
\text { picking }\end{array}$ & $\begin{array}{l}\text { peak- } \\
\text { picking }\end{array}$ & $\begin{array}{l}\text { curve- } \\
\text { fitting }\end{array}$ & $\begin{array}{l}\text { curve- } \\
\text { fitting }\end{array}$ & & \\
\hline substrate & solvent & $\begin{array}{l}\text { frequency } \\
\left(\mathrm{cm}^{-1}\right)\end{array}$ & $\begin{array}{c}\text { FWHM } \\
\left(\mathrm{cm}^{-1}\right)\end{array}$ & $\begin{array}{l}\text { frequency } \\
\left(\mathrm{cm}^{-1}\right)\end{array}$ & $\begin{array}{c}\text { FWHM } \\
\left(\mathrm{cm}^{-1}\right)\end{array}$ & $\begin{array}{l}\text { avg. electric } \\
\text { field } \\
(\mathrm{MV} / \mathrm{cm})\end{array}$ & $\begin{array}{c}\text { electric field } \\
\text { std. dev. (MV/cm) }\end{array}$ \\
\hline \multirow[t]{7}{*}{ ethyl acetate } & $\mathrm{D}_{2} \mathrm{O}$ & $1703.8 \pm 0.3$ & $35.9 \pm 0.8$ & $\begin{array}{l}1680.2 \pm 3.8 \\
1701.9 \pm 0.1 \\
1722.6 \pm 0.7\end{array}$ & $\begin{array}{l}33.0 \pm 9.2 \\
23.1 \pm 0.8 \\
32.7 \pm 0.9\end{array}$ & $-67.4 \pm 1.3$ & 22.5 \\
\hline & chloroform & $1731.6 \pm 0.3$ & $22.2 \pm 0.7$ & $\begin{array}{l}1710.5 \pm 0.4 \\
1731.4 \pm 0.1\end{array}$ & $\begin{array}{l}18.7 \pm 0.7 \\
20.8 \pm 0.3\end{array}$ & $-29.3 \pm 0.7$ & 14.1 \\
\hline & DCM & $1733.5 \pm 0.1$ & $16.7 \pm 1.2$ & $\begin{array}{l}1717.5 \pm 0.3 \\
1733.5 \pm 0.2\end{array}$ & $\begin{array}{l}13.8 \pm 0.8 \\
15.7 \pm 1.2\end{array}$ & $-27.3 \pm 0.9$ & 12.8 \\
\hline & DMSO & $1732.7 \pm 0.1$ & $13.6 \pm 0.1$ & $1732.6 \pm 0.1$ & $13.9 \pm 0.1$ & $-26.2 \pm 0.5$ & 11.0 \\
\hline & THF & $1741.5 \pm 0.1$ & $11.4 \pm 0.9$ & $1741.5 \pm 0.2$ & $11.0 \pm 0.2$ & $-13.8 \pm 0.4$ & 7.9 \\
\hline & dibutyl ether & $1746.2 \pm 0.1$ & $10.6 \pm 0.9$ & $1746.3 \pm 0.1$ & $10.5 \pm 0.1$ & $-6.8 \pm 0.2$ & 5.3 \\
\hline & Hexanes & $1750.2 \pm 0.1$ & $9.9 \pm 0.2$ & $1750.3 \pm 0.1$ & $9.9 \pm 0.2$ & $-0.1 \pm 0.1$ & 0.8 \\
\hline \multirow[t]{7}{*}{ methyl benzoate } & $\mathrm{D}_{2} \mathrm{O}$ & $1704.6 \pm 0.9$ & $28.9 \pm 0.3$ & $\begin{array}{l}1686.0 \pm 1.6 \\
1704.8 \pm 0.5\end{array}$ & $\begin{array}{l}18.3 \pm 1.5 \\
25.9 \pm 0.8\end{array}$ & $-60.3 \pm 1.6$ & 22.1 \\
\hline & chloroform & $1720.2 \pm 0.1$ & $19.7 \pm 0.1$ & $\begin{array}{l}1712.0 \pm 0.2 \\
1721.5 \pm 0.1\end{array}$ & $\begin{array}{l}15.9 \pm 0.7 \\
14.5 \pm 0.2\end{array}$ & $-22.4 \pm 1.3$ & 13.9 \\
\hline & DCM & $1720.6 \pm 0.1$ & $14.4 \pm 0.1$ & $1720.7 \pm 0.1$ & $14.7 \pm 0.1$ & $-22.2 \pm 0.4$ & 12.5 \\
\hline & DMSO & $1719.7 \pm 0.1$ & $12.4 \pm 0.2$ & $1719.6 \pm 0.1$ & $12.6 \pm 0.2$ & $-17.1 \pm 0.2$ & 10.0 \\
\hline & THF & $1727.5 \pm 0.4$ & $8.0 \pm 0.8$ & $1727.3 \pm 0.4$ & $7.9 \pm 0.8$ & $-9.5 \pm 0.4$ & 7.3 \\
\hline & dibutyl ether & $1731.4 \pm 0.4$ & $7.4 \pm 0.1$ & $1731.4 \pm 0.1$ & $7.4 \pm 0.1$ & $-4.9 \pm 0.3$ & 5.2 \\
\hline & hexanes & $1734.4 \pm 0.1$ & $5.8 \pm 0.2$ & $1734.6 \pm 0.1$ & $5.9 \pm 0.1$ & $-0.1 \pm 0.1$ & 0.8 \\
\hline \multirow[t]{7}{*}{ ethyl thioacetate } & $\mathrm{D}_{2} \mathrm{O}$ & $1663.3 \pm 0.7$ & $42.0 \pm 0.7$ & $1662.6 \pm 0.2$ & $41.5 \pm 0.5$ & $-67.9 \pm 1.7$ & 21.6 \\
\hline & chloroform & $1684.9 \pm 0.2$ & $24.7 \pm 0.1$ & $1683.8 \pm 0.2$ & $25.2 \pm 0.2$ & $-27.8 \pm 0.5$ & 13.3 \\
\hline & DCM & $1686.8 \pm 0.1$ & $18.7 \pm 0.4$ & $1686.9 \pm 0.1$ & $19.3 \pm 0.4$ & $-25.7 \pm 0.7$ & 12.4 \\
\hline & DMSO & $1686.2 \pm 0.1$ & $16.9 \pm 0.1$ & $1685.8 \pm 0.1$ & $17.2 \pm 0.2$ & $-24.4 \pm 0.4$ & 11.3 \\
\hline & THF & $1693.9 \pm 0.1$ & $12.9 \pm 0.4$ & $1693.9 \pm 0.1$ & $13.2 \pm 0.3$ & $-12.4 \pm 0.3$ & 8.1 \\
\hline & dibutyl ether & $1697.8 \pm 0.1$ & $13.1 \pm 1.0$ & $1698.7 \pm 0.3$ & $13.0 \pm 0.9$ & $-5.9 \pm 0.2$ & 5.6 \\
\hline & hexanes & $1701.0 \pm 0.1$ & $10.3 \pm 0.1$ & $1701.2 \pm 0.1$ & $10.4 \pm 0.1$ & $-0.1 \pm 0.1$ & 0.7 \\
\hline \multirow[t]{7}{*}{ butyl thiobenzoate } & $\begin{array}{l}1: 2\left(\begin{array}{ll}\% & \mathrm{v} / \mathrm{v}) \\
\mathrm{DMSO} / \mathrm{D}_{2} \mathrm{O}^{a}\end{array}\right.\end{array}$ & 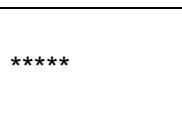 & $* * * * *$ & $\begin{array}{l}1628.3 \pm 1.9 \\
1645.4 \pm 0.3 \\
1662.6 \pm 0.1\end{array}$ & $\begin{array}{l}34.7 \pm 2.2 \\
19.1 \pm 0.4 \\
17.5 \pm 0.3\end{array}$ & $-59.5 \pm 2.2^{b}$ & $21.9^{b}$ \\
\hline & chloroform & $1659.2 \pm 0.1$ & $19.2 \pm 3.1$ & $1659.4 \pm 0.4$ & $17.1 \pm 2.2$ & $-20.2 \pm 1.2$ & 13.6 \\
\hline & DCM & $1660.4 \pm 0.1$ & $18.6 \pm 0.4$ & $1660.2 \pm 0.1$ & $18.9 \pm 0.4$ & $-21.0 \pm 0.2$ & 12.2 \\
\hline & DMSO & $1659.6 \pm 0.1$ & $18.5 \pm 0.4$ & $1659.9 \pm 0.2$ & $19.3 \pm 0.4$ & $-15.8 \pm 0.5$ & 10.5 \\
\hline & THF & $1666.3 \pm 0.1$ & $9.6 \pm 0.1$ & $1666.2 \pm 0.1$ & $10.3 \pm 0.4$ & $-8.9 \pm 0.2$ & 7.4 \\
\hline & dibutyl ether & $1670.2 \pm 0.1$ & $9.0 \pm 0.1$ & $1670.0 \pm 0.1$ & $9.1 \pm 0.1$ & $-4.2 \pm 0.4$ & 5.1 \\
\hline & hexanes & $1672.6 \pm 0.1$ & $6.1 \pm 0.1$ & $1672.5 \pm 0.1$ & $6.1 \pm 0.1$ & $-0.1 \pm 0.1$ & 0.7 \\
\hline \multirow[t]{2}{*}{$\begin{array}{l}, N- \\
\text { dimethylacetamide }\end{array}$} & $\mathrm{D}_{2} \mathrm{O}$ & $1607.4 \pm 0.1$ & $20.2 \pm 0.1$ & $1607.7 \pm 0.1$ & $20.6 \pm 0.1$ & $-99.2 \pm 2.3$ & 21.3 \\
\hline & chloroform & $1633.0 \pm 0.2$ & $24.5 \pm 1.0$ & $\begin{array}{l}1633.4 \pm 0.2 \\
1651.2 \pm 0.8\end{array}$ & $\begin{array}{l}22.1 \pm 0.8 \\
23.7 \pm 2.1\end{array}$ & $-42.4 \pm 0.7$ & 12.9 \\
\hline
\end{tabular}




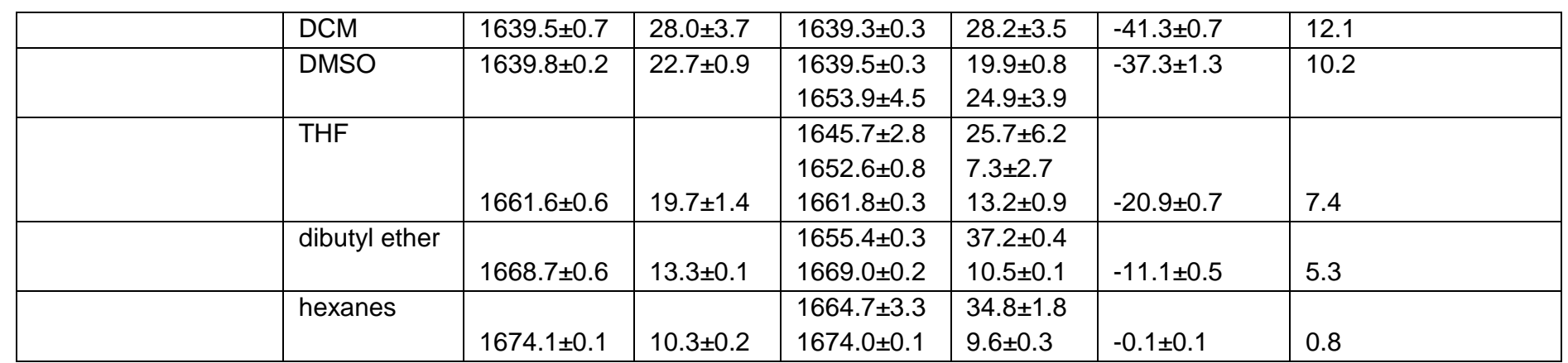

${ }^{a} 1: 2(\% \mathrm{v} / \mathrm{v})$ DMSO: $\mathrm{D}_{2} \mathrm{O}$ was chosen as an estimate for the frequency observed in $\mathrm{D}_{2} \mathrm{O}$ due to the poor solubility of butyl thiobenzoate in $\mathrm{D}_{2} \mathrm{O} .{ }^{b}$ Electric fields and standard deviations correspond to those calculated in $\mathrm{D}_{2} \mathrm{O}$.

Table S2. Comparison of the Stark tuning rate and local field factor from VSS and field-frequency correlations.

\begin{tabular}{|l|c|c|c|}
\hline solute & $\begin{array}{c}\left|\Delta \vec{\mu}_{C=o}\right| f^{a} \\
{\left[\mathrm{~cm}^{-1} /(\mathrm{MV} / \mathrm{cm})\right]}\end{array}$ & $\begin{array}{c}\left|\Delta \vec{\mu}_{C=O}\right|^{b} \\
{\left[\mathrm{~cm}^{-1} /(\mathrm{MV} / \mathrm{cm})\right]}\end{array}$ & $f^{c}$ \\
\hline ethyl acetate & 1.15 & 0.70 & 1.6 \\
\hline ethyl thioacetate & 1.47 & 0.56 & 2.6 \\
\hline methyl benzoate & 1.15 & 0.48 & 2.4 \\
\hline butyl thiobenzoate & 1.37 & 0.56 & 2.4 \\
\hline $\begin{array}{l}N, N- \\
\text { dimethylacetamide }\end{array}$ & 1.30 & 0.70 & 1.8 \\
\hline
\end{tabular}

${ }^{a}$ The Stark tuning rate as determined from vibrational Stark spectroscopy (VSS) (Table 2). ${ }^{b}$ The Stark tuning rate as determined from correlation the slope of the field-frequency correlations (Figure 3). ${ }^{c}$ The local field factor as determined from $\left|\Delta \vec{\mu}_{C=o}\right| f /\left|\Delta \vec{\mu}_{C=O}\right|$ from the two approaches described in the text.

\section{References:}

(1) Fried, S. D.; Wang, L. P.; Boxer, S. G.; Ren, P.; Pande, V. S. Calculations of the Electric Fields in Liquid Solutions. J. Phys. Chem. B 2013, 117, 16236-16248. 